\title{
GIS-based examination of peats and soils in Surfers Paradise, Australia
}

\begin{abstract}
The subsoil conditions of Surfers Paradise in Southeast Queensland of Australia have been examined in terms of soil stiffness by using geographic information system (GIS). Peat is a highly organic and compressible material. Surfers Paradise (as a study area) has problematic peat layer due to its high water content, high compressibility, and low shear strength. This layer has various thicknesses at different locations ranging between R.L. -10 to R.L. -19.6 m. Buildings in Surfers Paradise are using piled foundations to avoid the high compressibility and low shear strength peat layer. Spatial Analyst extension in the GIS ArcMap10 has been utilised to develop zonation maps for different depths in the study area. Each depth has been interpolated as a surface to create Standard Penetration Test SPT- $N$ value GIS-based zonation maps for each depth. In addition, 8 interpolation techniques have been examined to evaluate which technique gives better representation for the Standard Penetration Test (SPT) data. Inverse Distance weighing (IDW) method in Spatial Analyst extension gives better representation for the utilised data with certain parameters. Two different cross sections have been performed in the core of the study area to determine the extent and the depth of the peat layer underneath already erected buildings. Physical and engineering properties of the Surfers Paradise peat have been obtained and showed that this peat falls within the category of tropical peat.
\end{abstract}

Key words: GIS, IDW, Peat, SPT- $N$, Zonation Map

\section{INTRODUCTION}

Geotechnical data is hard and expensive to be obtained as it can be acquired by costly boring investigations. Because of the escalating cost of soil investigation throughout the world, and due to the budgetary constraints, small projects are often overlooked the site characterization (Ho and Skeels 2003). Geographic Information System (GIS) has been used as a vital tool in the classification of soils in recent years for variety of applications. GIS can be used for data management and site investigation (Deaton et al. 2001; Kunapo et al. 2005). In addition, GIS has also been used to facilitate zonation maps production and to estimate if a further precaution is required for a safer area in terms of foundation stability in Turkey (Orhan and Tosun 2010). In terms of soil pedology, L'Abate et al. (2013) developed a GIS web based geotechnical information system for the Italian soil data applications. This system has been used for soil pedologic unit's observation and for the dissemination and consultation of soil information for diverse purposes. Moreover, Udomsri (2006) used the remote sensing data in GIS environment for the purpose of mapping soil on slopes and inaccessible areas that prone to soil erosion in Doi Ang Khang area in Thailand.
Peat is an unconsolidated organic material consisting largely of organic residues accumulated as a result of incomplete decomposition of dead plant remains under conditions of excessive moisture (Landva 2007). Peat has an adverse effect on the settlement of foundations and the raft foundations in particular, where the highly compressive peat can produce excessive settlements for buildings erected above it ( $\mathrm{Oh}$ et al. 2008). Santagata et al. (2008) stated that soils with high organic matter content are normally with high rates of creep, high compressibility, associated risk of inadmissible settlements and unsatisfactory strength properties as well as probable foundation failure. Based on the available data in the study area, many tall buildings in Surfers Paradise, Australia are supported by rafted pile and pile foundations (Oh et al. 2008) as a measure to avoid the peat layer underneath those buildings.

In terms of soil pedological classification, the soil in the study area is containing of Arenic Rudosols (RU-AO) young siliceous soil, weakly coherent, freely draining, partially indurated layers at depth, neglible pedologic Organisation Aeric Podosols (PO-AL) horizon accumulation organic matter, iron and aluminium (GCCC 2011). Pedologically speaking, the parent materials of the soil in the study area comprise 
of beach ridges related to the Holocene epoch which are, in turn, consisting of coarse textured quartzitic and shelly sand. Many of these beach ridges and associated low dunes typically have weakly developed podzol horizons where soils are acidic. These frontal beach ridges, dunes, and calcareous coral cays may have minimal sub-soil horizon development (Wilson and Tylor 2012).

In this paper, GIS- based SPT-N value zonation maps have been established by utilising the Spatial Analyst IDW method based on the field data collected. The purpose of this is to determine the extent, depth, and the characteristics of the peat layer in the study area. This is, in turns, to assist designers and researchers to have an idea about peat occurrence locations and to predict the SPT-N value in locations lack of sampled points. Comparison between the 8 interpolation methods has been conducted to identify which technique gives better representation for the soil data in the study area among the other interpolation techniques.

\section{MATERIALS AND METHODS}

Data has been collected from 51 soil investigation reports related to the already existed engineering structures in the study area. Table 1 shows summary of the study types which have been used to produce the SPT- $N$ value zonation maps and to extract the soil engineering properties. The total length of the 117 boreholes in depth (the summation of the borehole's depths in all locations) is $4096.5 \mathrm{~m}$. The deepest borehole reached to the depth of $46.45 \mathrm{~m}$ below the ground surface (R.L. - 40.1) which represents the depth of the bed rock in some locations in the study area. The Reduced Level (R.L.) is a calculated elevation of a specific point in relation to a particular datum.
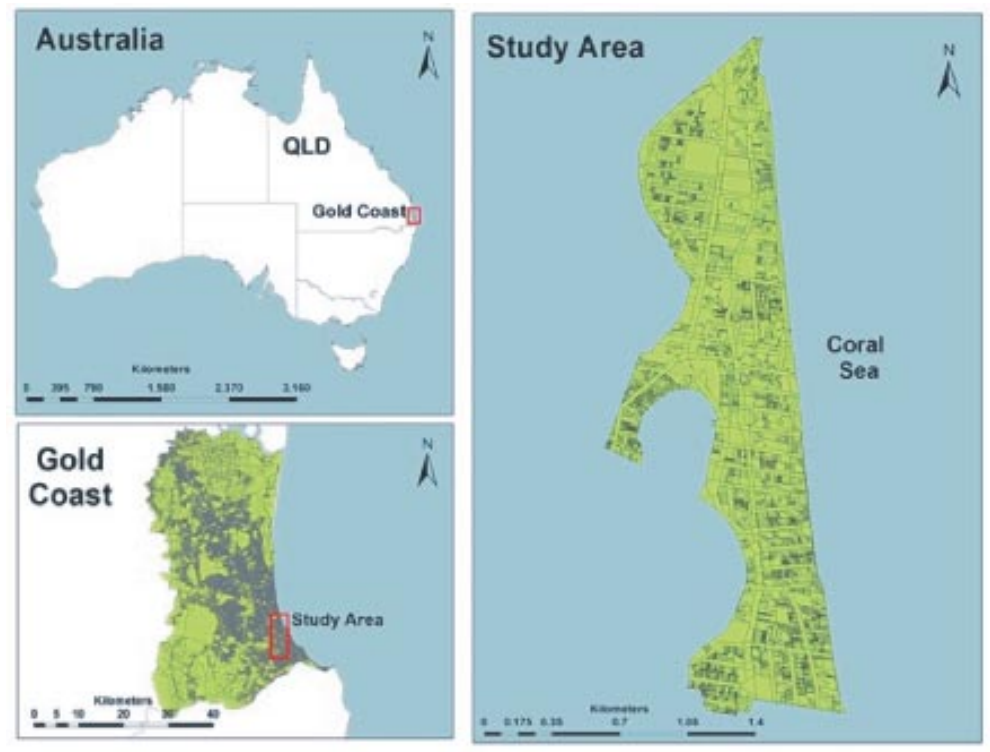

TABLE 1 . Summary of the study types used in the SPT- $N$ value zonation maps

\begin{tabular}{llc}
\hline Study Type & Unit & Value \\
\hline Soil Investigation Reports & Amount & 51 \\
Number of Boreholes & Amount & 117 \\
Deepest Borehole Depth & Metres & 46.45 \\
Total SPT-N Tests & Amount & 1754 \\
Interpolation Method & Amount & 8 \\
Interpolated Surfaces & Amount & 26 \\
Depth Class & Amount & 9 \\
Depth Subclass & Amount & 26 \\
\hline
\end{tabular}

As such, the R.L. used in this paper is calculated based on the Australian Height Datum (AHD). The reason of selecting the SPT- $N$ value in the developing of the zonation maps is because of the Abundance of the SPT data in the study area.

Surfers Paradise (the study area) has an area of about 4 by $1.3 \mathrm{~km}^{2}$ and the Nerang River divides this area into two main parts: Nerang River part and beach side part (Figure 1). The study area lies in the beach side part of the Surfers Paradise area. This part has the highest rise buildings and skyscrapers such as the Q1 tower (Queensland number 1) which is considered as the tallest building in Australia and one of the tallest buildings in the world. The study area is located between $27.98^{\circ}$ and $28.01^{\circ}$ Southing and between $153.41^{\circ}$ and $153.43^{\circ}$ Easting based on the projection of Universal Transverse Mercator UTM zone 56. This part also has the majority of tourist activities and population. The study area is bounded by two important water bodies: Nerang River from the east and the Coral Sea form the west. These aquatic bodies have a direct impact on the physical and engineering properties of the soil and peat in the study area.

Two approaches have been used to produce the GIS based zonation maps and to determine the extent of the peat layer in the study area. The first approach was to obtain the most relevant data to be investigated and organised. As such, data has undergone to conversion processes because most of the data were in different units and formats. After that, data has been tabulated by using Microsoft Excel to make this data consistent with the GIS environment. Each borehole has been given coordinates based on its geographical location; these coordinates have been obtained from Google Earth based on each project's site plan. The designation of boreholes coordinates has been done through accurate

FIGURE 1 . The location of the study area 
measurements with reference to the project's site plan. By calculating the distances between separate boreholes, the location of boreholes and building boundaries, the coordinates of each point can be easily obtained from Google Earth. Randomly selected points have been checked by using GPS to validate the coordinates obtained from Google Earth.

To facilitate the GIS-based SPT-N zonation maps drawing, Depth Classification Scheme (DCS) has been designed for different depth levels in the study area. The depth has been classified into 9 classes with an interval of every 5 meters except for the first depth was $7 \mathrm{~m}$ because it depends on the ground surface elevation. Each class consists of three subclasses starting from the ground surface till depth R.L. $-40 \mathrm{~m}$.

The second approach was to make a comparison among eight interpolation techniques to examine which technique can provide a better representation for the investigated data. These techniques which are under the Spatial Analyst extension in ArcMap10 have been used to develop the GIS-based SPT- $N$ value zonation map for each depth. The geotechnical characteristic examined in this study is the Standard Penetration Test SPT- $N$ value which is an indicator of soil stiffness. The stiffness values of the soil types in this paper have been categorized based on (Look 2007).

The 8 interpolation techniques utilised in this study were: spatial analyst Inverse Distance Weighting IDW, geostatistical IDW, Ordinary Kriging Universal Kriging, Spline, Diffusion, Global Polynomial, and Kernel. These methods have been chosen as interpolation techniques to obtain new SPT- $N$ values in locations lack of sampled points. The interpolation techniques represent spatial geostatistical analyst extensions in the ArcMap.

\section{RESULTS}

The subsoil profile of the Surfers Paradise comprises of loose to medium dense sand from the ground surface until R.L. $2.3 \mathrm{~m}$. After that a layer of medium dense sand to dense sand between R.L. 2.3 to $-3.2 \mathrm{~m}$ is found. Then a layer of very dense sand is existed between R.L. -3.2 to $-20 \mathrm{~m}$. Within the very dense sand layer, a varying thickness peat layer occurred at depth between R.L. -10 to R.L. $-19.6 \mathrm{~m}$ at different locations with thickness ranges from $0.1-7.0 \mathrm{~m}$. An interbedded firm to very stiff clay layers were encountered up to R.L. $-26.6 \mathrm{~m}$ where a layer of firm to hard clay is located underneath it until the depth R.L. $29 \mathrm{~m}$. The last layer in this soil profile differs within the study area where in some locations that an interbedded layer consists of medium dense sand, gravelly sand, clayey sand, sandy clay or hard silty clay can be found. This subsoil profile is consistent with the description given by Oh et al. (2008) and Al-Ani et al. (2013a, c, d).

In terms of spatial analysis in GIS, a comparison among 8 interpolation methods has been done to determine which technique provides a better representation for the examined data. The results showed that the most suitable spatial interpolation method that provides a better representation of the SPT- $N$ value data was the spatial analyst interpolation IDW with certain parameters. These parameters are: output cell size is " $2.719 \mathrm{E}^{-05}$ ", power is " 2 ", search radius is "fixed" and distance is " 0.25 ". These parameters are consistent with Al-Ani et al. (2013a, b) and Al-Ani et al. (2014). As such, two examples of this comparison have been presented in this paper (Figure 2 and 3). The IDW method is one of the most repeatedly used deterministic model in spatial interpolation by geoscientists (Lu and Wong 2008). In addition, this finding is consistent with Gotway et al. (1996) and Orhan and Tosun (2010). Based on visual inspection, it can be clearly observed that Figures $2 \mathrm{~B}$ and 3B represent smooth and homogenous distribution of the SPT-N values compared with Figures $2 \mathrm{~A}$ and $3 \mathrm{~A}$. In other words, zones of SPT- $N$ value can be clearly recognised in the zonation maps produced by IDW compared with other interpolation techniques. Al-Ani et al. (2014) presented detailed comparisons among the 8 interpolation methods and their resulting zonation maps.

This paper provides four different interpolated surfaces (maps) at four different depth levels within the study area produced by the IDW technique in the Spatial Analyst extension in Arc Map. The reason of developing these zonation maps is to show the distribution of the SPT- $N$ values in the study area and to interpolate new SPT-N values in locations lack of sampled points. The first interpolated zonation map is located at depth between R.L. 0 to R.L. $-1.6 \mathrm{~m}$ (Figure 4). In this zonation map, data has been collected from 81 boreholes and the SPT- $N$ values ranged between 0 to $\geq 50$ blows and the soil type is generally characterized by medium dense sand to very dense sand. Some locations have very loose sand in the northern east parts of the study area which are close to Nerang River whereas, two other locations have very soft organic clay and hard clay with SPT- $N$ value 0 and 50 blows respectively in the core of the study area.

The second zonation map shows the variation in the $N$ value within the depth of R.L. -8.3 to R.L. $-10 \mathrm{~m}$ (Figure 5). In this depth, data has been collected from 70 boreholes within the study area. The SPT- $N$ valu- 


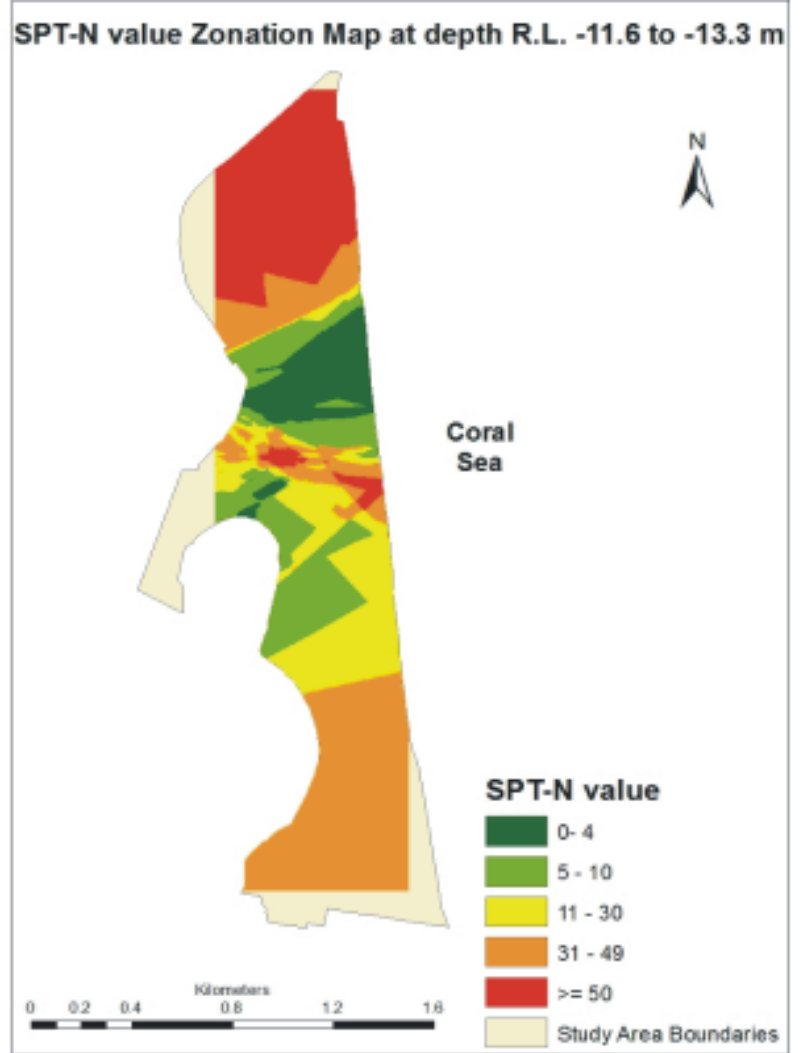

A

FIGURE 2. Comparison between Spatial Analyst, Ordinary Kriging and Spatial Analyst IDW interpolation methods at the same depth: A - Spatial Analyst, Ordinary Kriging, B - Spatial Analyst, IDW

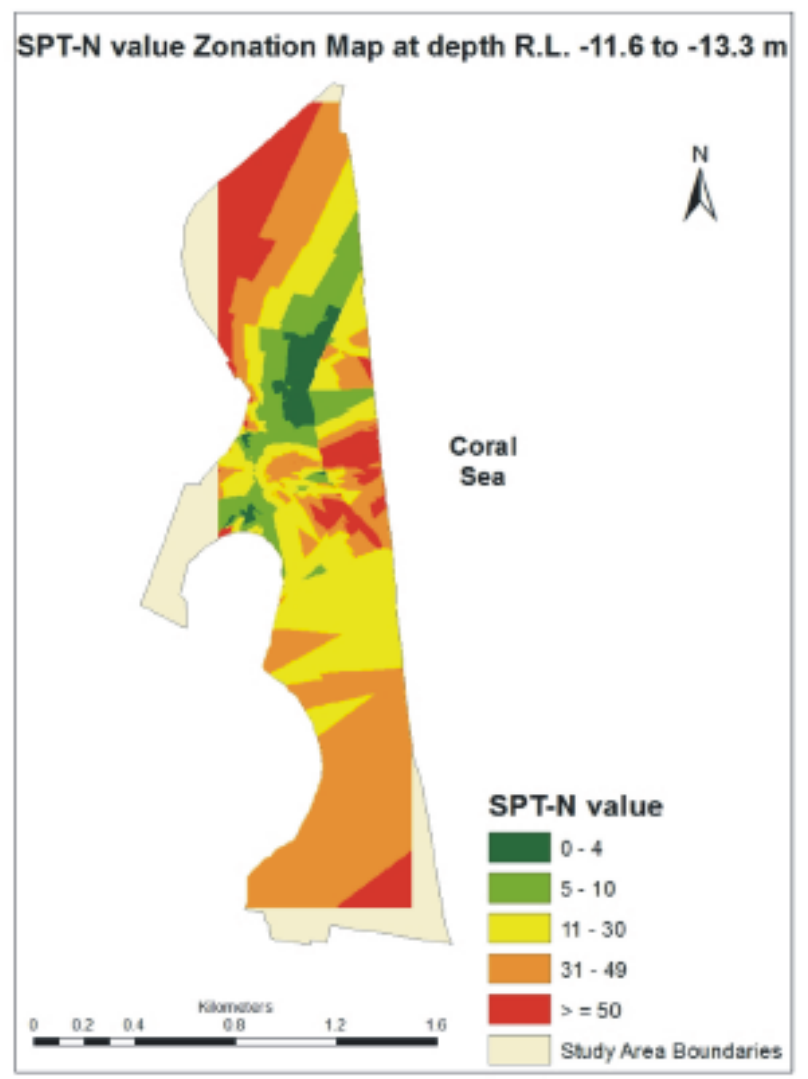

A

FIGURE 3. Comparison between Spatial Analyst, Universal Kriging and Spatial Analyst IDW interpolation methods at the same depth: A - Spatial Analyst, Universal Kriging,B - Spatial Analyst, IDW

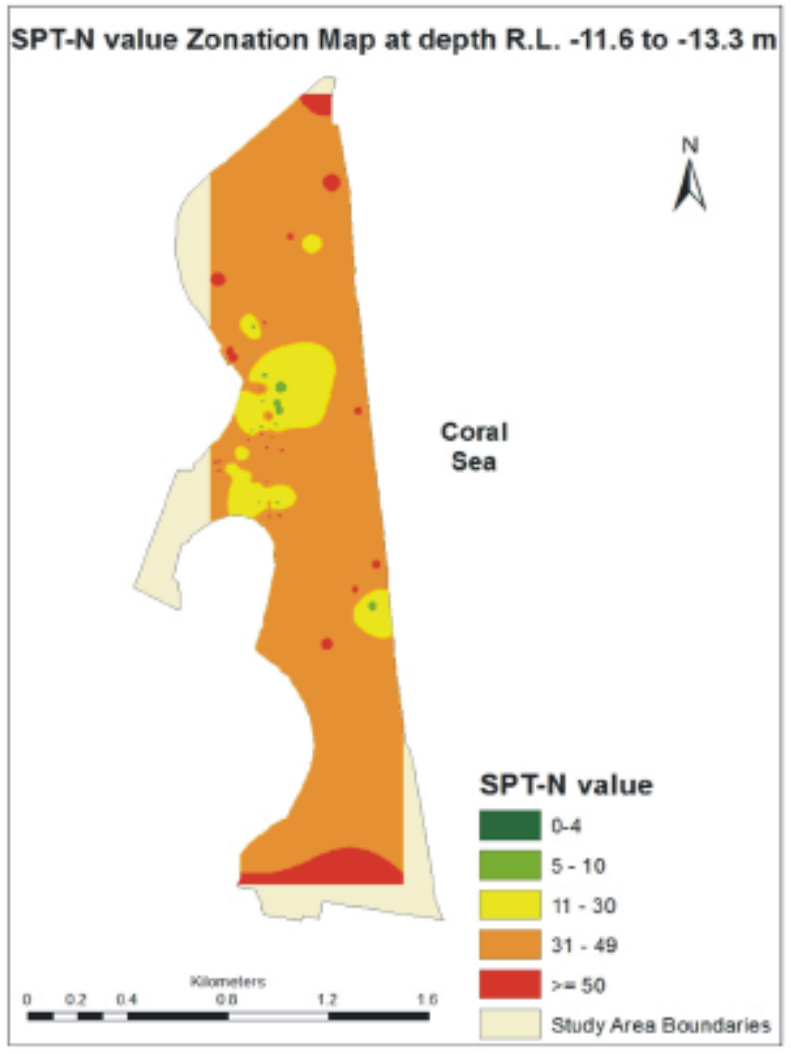

B

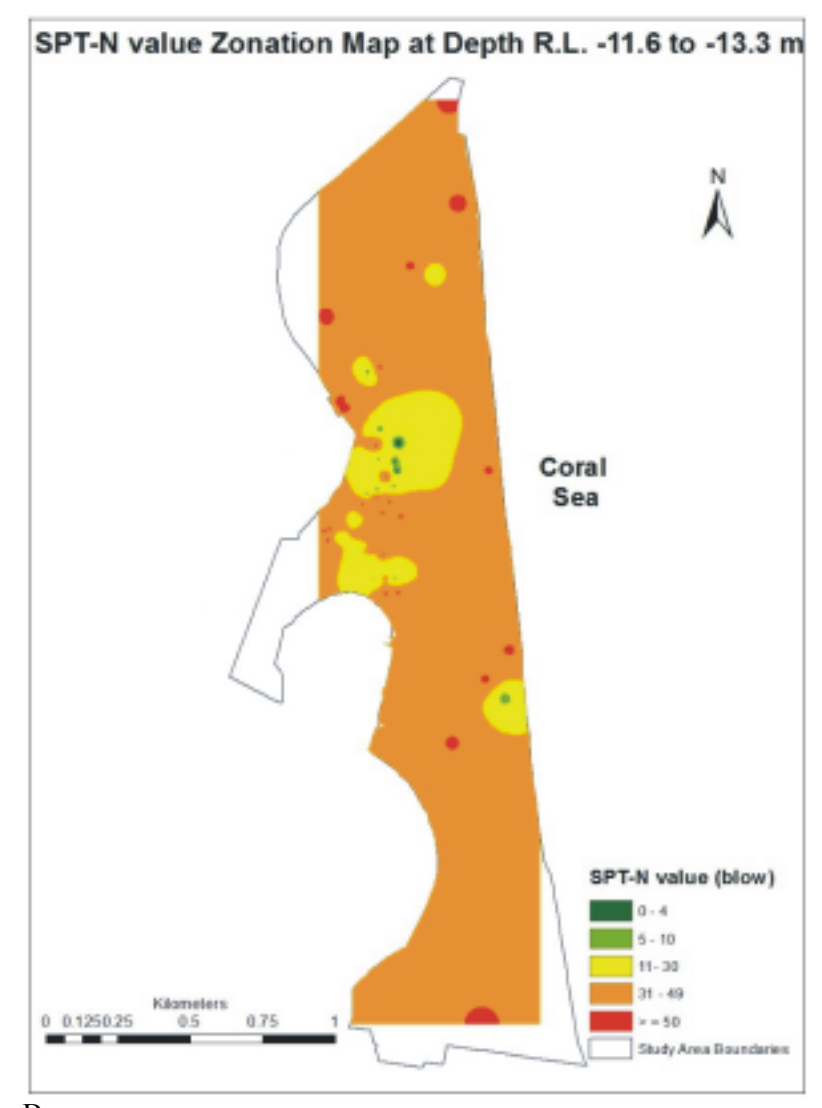

B 


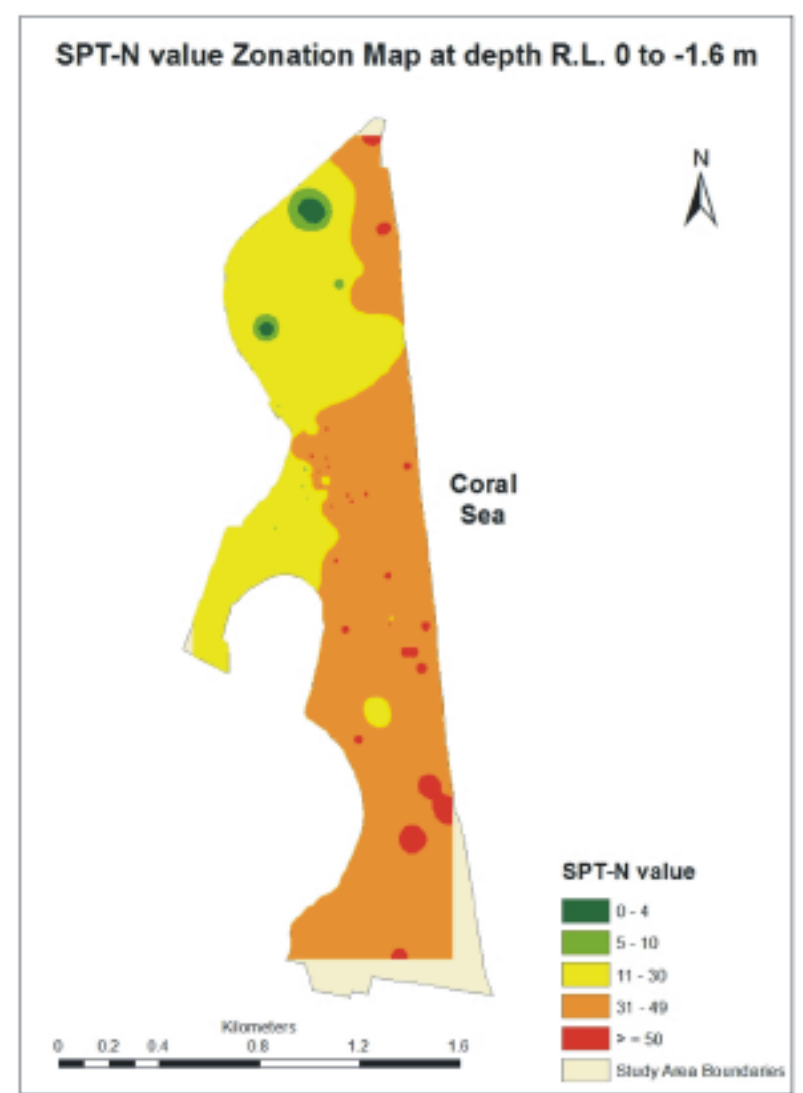

FIGURE 4. SPT- $N$ value zonation map for the depth of R.L. (0.0)-(-1.6) m

es ranged from 13 to 50 blows consisting generally of very dense sand. Three locations contain medium dense sand with $N$ values ranged between 13 and 26 blows. In addition, four locations comprise dense sand with $N$ values ranged from 33-43 blows. Peat occurs in the core of the study area with an $N$ value of 6 blows and has a thickness of $2 \mathrm{~m}$ from R.L. -10 to $-12 \mathrm{~m}$.

The third zonation map shows the difference of the $N$ value within the depth of R.L. -10 to R.L. $-11.6 \mathrm{~m}$ from 57 boreholes within the study area (Figure 6). The SPT- $N$ value fluctuates between 0 to $\geq 50$ blows and the soil type is mostly characterized by very dense sand with an interbedded peat. The low $N$ values reflect the existence of peat in 19 boreholes; these values were between $0-22$ blows. The peat thickness in this depth level is between 1.2 to $2.8 \mathrm{~m}$ except in the east and the south of the study area where the thickness was $0.4 \mathrm{~m}$ and $5.0 \mathrm{~m}$ respectively.

The fourth zonation map is related to the depth of R.L. -16.6 to R.L. $-18.3 \mathrm{~m}$ and data has been collected from 66 boreholes within the study area (Figure 7). Mainly, the SPT- $N$ value is greater than or equal to 50 blows in all over the study area at this depth level which reflect the occurrence of very dense sand. However, there are two locations show peat existence with an $N$ value of between $12-15$ blows. The peat thick-

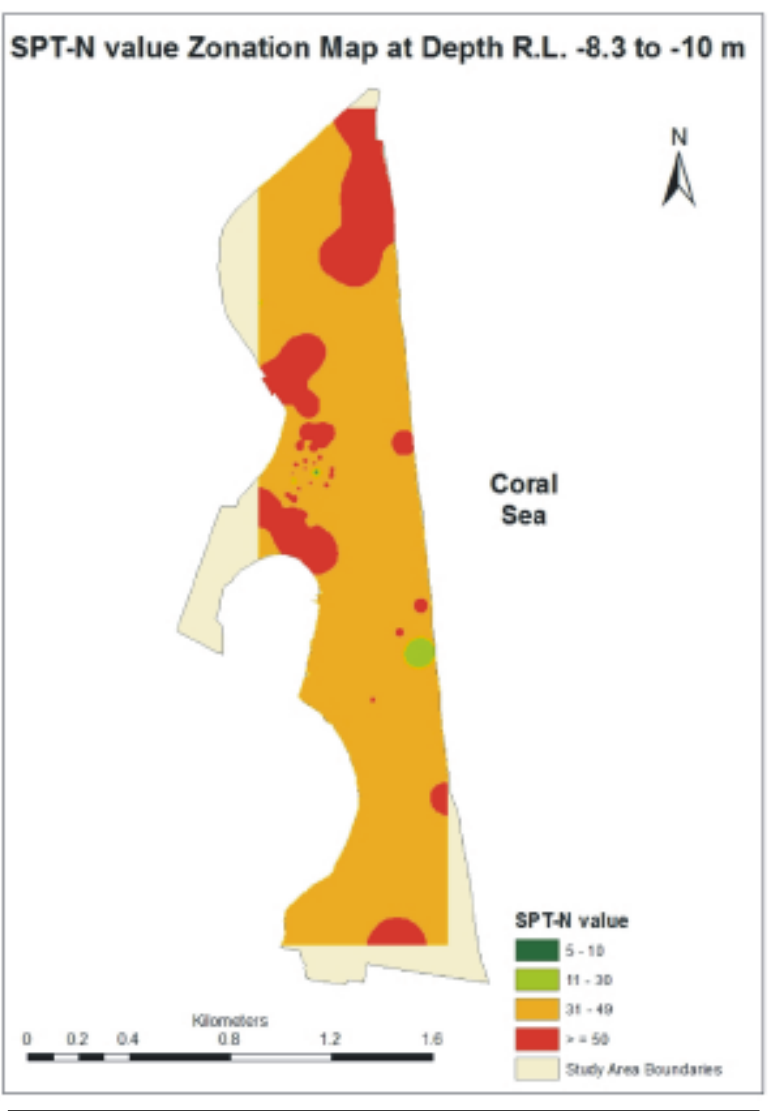

FIGURE 5. SPT-N value zonation maps for the depth of R.L. $(-8.3)-(-10) \mathrm{m}$

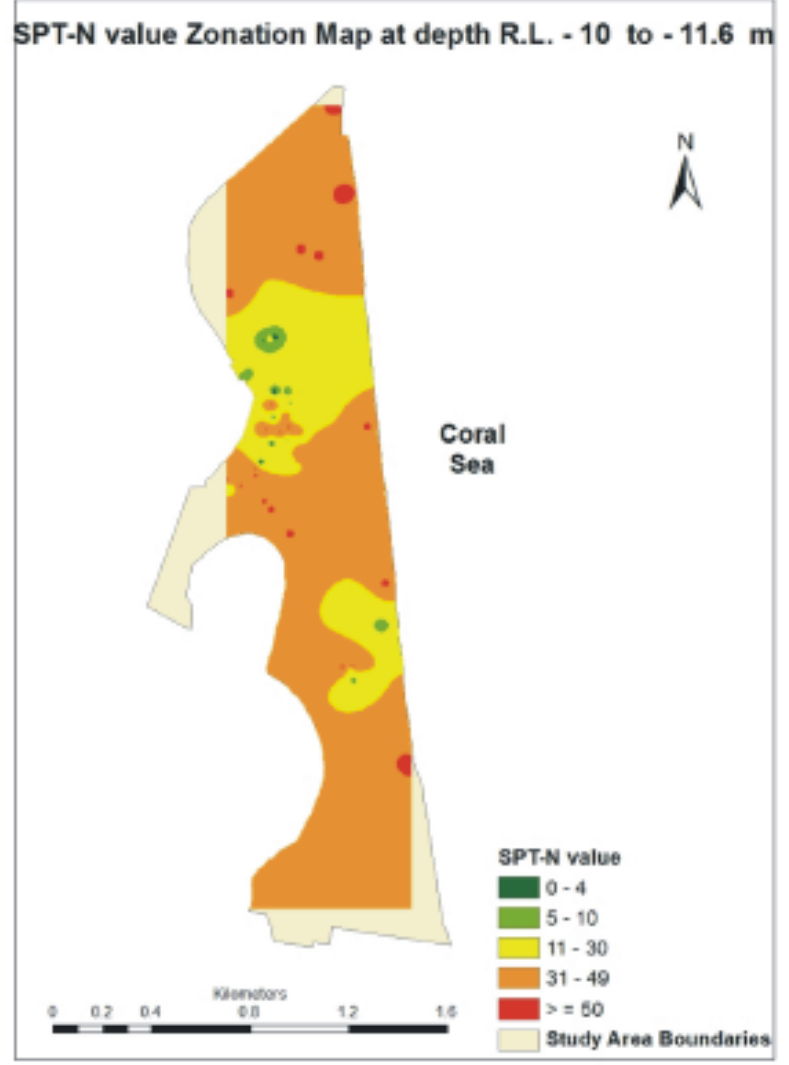

FIGURE 6. SPT- $N$ value zonation maps for the depth of R.L. $(-10)-(-11.6) \mathrm{m}$ 


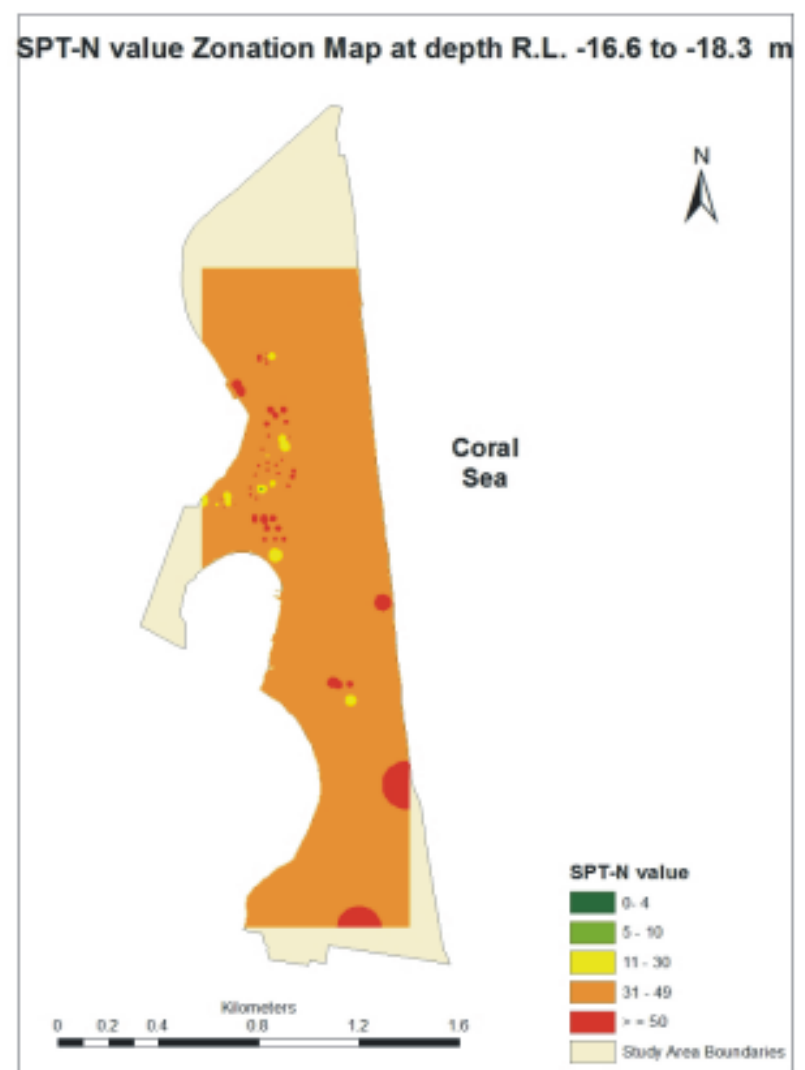

FIGURE 7. SPT- $N$ value zonation maps for the depth of R.L. $(-16.6)-(-18.3) \mathrm{m}$

ness is 0.45 and $4.0 \mathrm{~m}$ in the eastern parts of the study area close to the Nerang River. Moreover, sandy clay, sandy silty clay, and silty clay were also observed with an $N$ value of between 8-29 blows.

It can be seen from these zonation maps there are areas without interpolated outputs on the produced zonation maps. This is because there is no sufficient data available in those areas to perform the interpolation process. Thus, the empty parts within the study area boundary and around the zonation maps denote no data sites.

Additionally, the extent and the depth of the peat layer in the study area have been determined. This has been achieved by performing two different directions cross sections (Figure 8) in the core (centre) of the study area where most of the high rise building are erected. The first cross section has been plotted in north-south direction within the core of the study area. This cross section passes through 17 boreholes related to 4 already existed high rise buildings for a distance of $576 \mathrm{~m}$ (Figure 9). The distan-

FIGURE 8. Cross sections directions and locations in the study area ce between these boreholes ranged between 20 to 45 $\mathrm{m}$ but in only two locations the distance was $55 \mathrm{~m}$ and $78 \mathrm{~m}$. The vertical and the horizontal scale of this cross section were $1: 250$ and 1:2,500 respectively and it has been done by using AutoCAD 2013. This cross section shows the horizontal variation in the thickness of the peat layer underneath the buildings in the study area. The thickness of the peat layer within this cross section was between 0.1 to $6.0 \mathrm{~m}$. As such, the lowest thickness of the peat layer was at depth R.L. -9.7 $\mathrm{m}$ and described as an amorphous black peat whereas, the thickest peat occurrence was at depth R.L. -15.7 and described as moist peat, low plasticity, dark brown, with decaying vegetation and logs.

The second cross section has been performed in approximately east-west direction within the core of the study area. This cross section passes through 11 boreholes related to 4 already erected high rise buildings for a distance of $462 \mathrm{~m}$ (Figure 10). The distance between these boreholes ranged between 10 to $35 \mathrm{~m}$ but only in four locations the distance was between 50 and $110 \mathrm{~m}$. The vertical and the horizontal scale of this cross section were 1:200 and 1:2,000 respectively. This cross section shows the horizontal variation in the thickness of peat with depth underneath already existed buildings. The thickness of the peat along this cross section was between 0.3 to $5.8 \mathrm{~m}$. The thinnest occurrence of peat was at the depth of between R.L. -12 to R.L. $-12.3 \mathrm{~m}$ and described as peat intrusions. Whereas, the thickest peat existence was at the depth of between R.L. -12.4 to R.L. $-18.2 \mathrm{~m}$ and described as black, amorphous with wood fragments. As mentioned previously, many of the tall buildings, including the Q1 tower are located in the centre of the study area within these two cross sections.

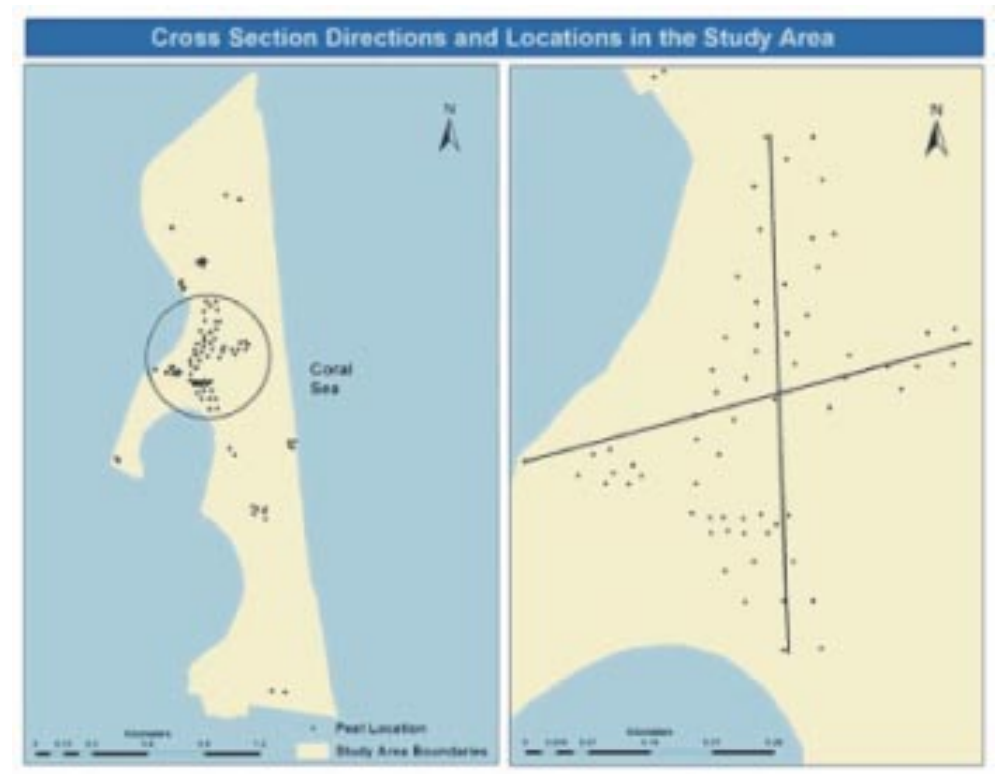




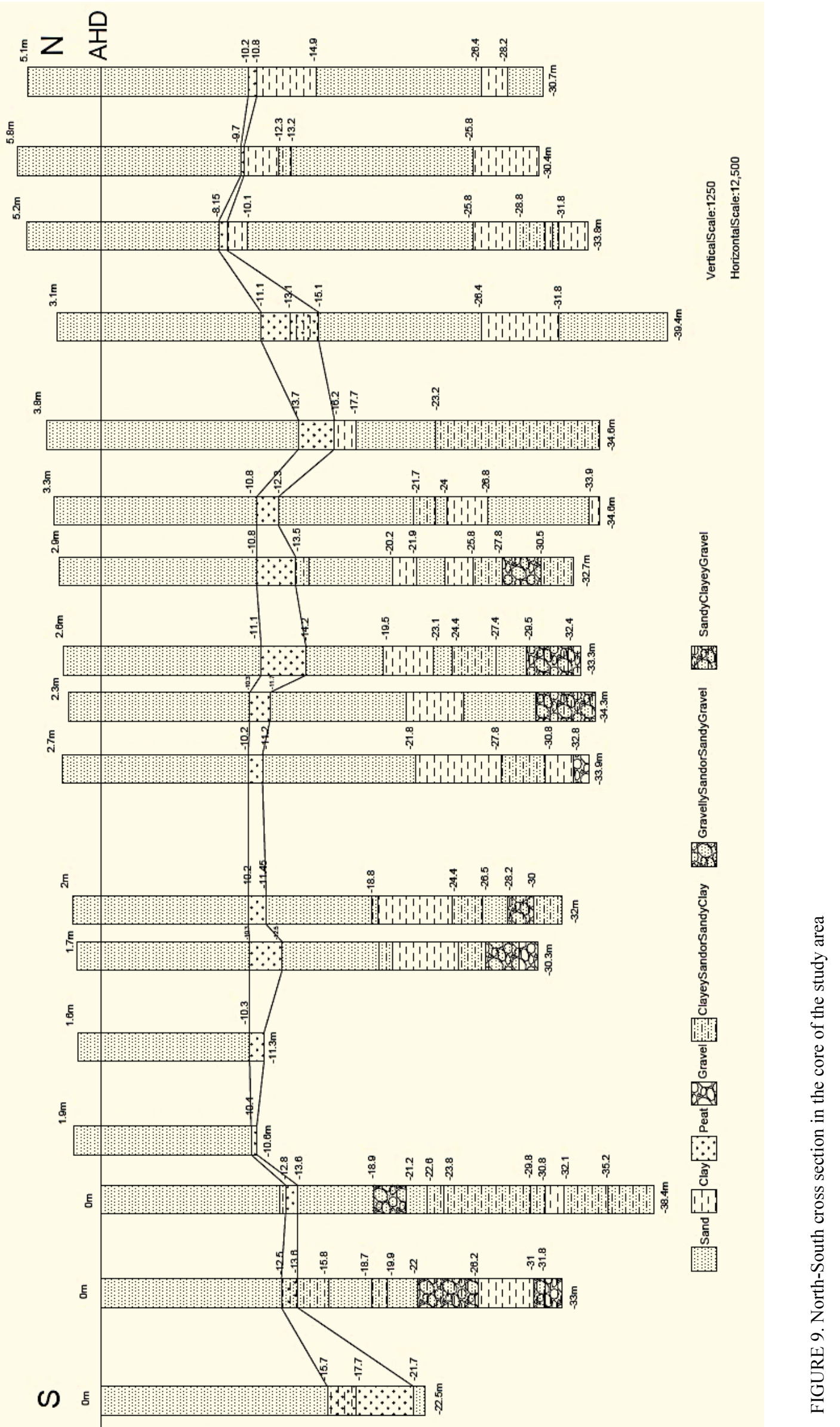




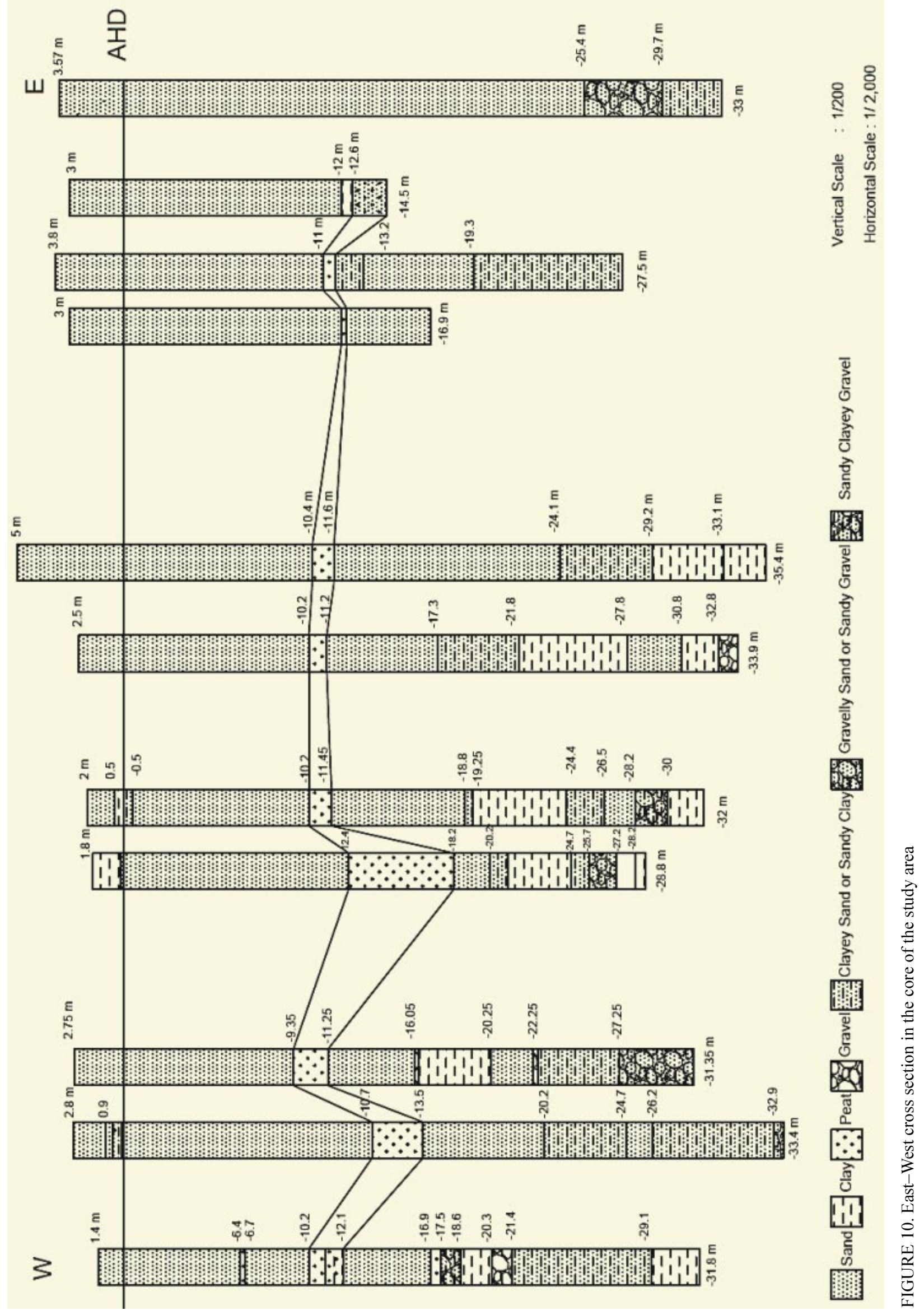


Moreover, physical and engineering properties of the peat layer have been obtained from the soil investigation reports of the Surfers Paradise area Table 2. the literature (Huat 2004; Duraisamy et al. 2007; Huat et al. 2009) and showed that the peat in Surfers Paradise falls within the range of the tropical peat. The

TABLE 2. Summary of the physical and engineering properties of peat in Surfers Paradise

\begin{tabular}{llll}
\hline Parameter & Value & Parameter & Value \\
\hline Liquid Limit & $259-305 \%$ & $\begin{array}{l}\text { Coefficient of Secondary } \\
\text { Consolidation (estimated) }\end{array}$ & $0.029-0.044$ \\
\hline Plastic Limit & $125-207 \%$ & Void ratio (estimated) & $3.6-4.7 \%$ \\
\hline Plasticity Index & $88-134$ & Apparent Cohesion & $43-166 \mathrm{kPa}$ \\
\hline Water Content & $168-247 \%$ & Apparent Friction Angle & $0-14$ Degree \\
\hline Unit weight & $0.37-1.26 \mathrm{t}^{3}$ & Shear Strength & $30-40 \mathrm{kPa}$ \\
\hline Coefficient. of Consolidation & $1.12-11.6 \mathrm{~m}^{2} / \mathrm{year}$ & Specific Gravity & 1.572 \\
\hline Coefficient. of Volume Compressibility & $2.4 \mathrm{E}^{-04}-6.63 \mathrm{E}^{-04} \mathrm{~m}^{2} / \mathrm{kN}$ & Permeability & $9.6 \mathrm{E}^{-10}-2.40 \mathrm{E}^{-05} \mathrm{~m} / \mathrm{sec}^{-20}$ \\
\hline Compression Index & $0.25-1.229$ & Ash Content & $20 \%$ \\
\hline
\end{tabular}

\section{DISCUSSION}

It has been observed from the aforementioned results that there is a direct proportional relationship between the SPT- $N$ value and many other parameters. These parameters are: soil type, organic matter content, physical status of each soil type, and depth. In addition, it can be also seen that there is a consistency in the results performed using GIS methods with this direct relationship. For instance, in the SPT- $N$ value zonation maps; there are obvious transitions from the low $N$ value in the shallow depths (near the ground surface) towards a large number of blows in the deepest layers except in some certain locations. These transitions are clear when the interpolated surfaces (maps) showed a gradual change in the number of blows from the ground surface (very loose and loose sand with an $N$ value less than 10 blows and sometimes zero) to the deepest depths (very dense sand and gravel with an $\mathrm{N}$ value of more than or equals to 50 blows). Thus, the deeper the layer reflects the higher the soil stiffness and as a result, the greater corresponding SPT- $N$ values. During the preparation of the Excel sheets which are the input of the GIS zonation maps, it has been noticed that the minimum depth of the bed rock in the study area is R.L. $-27.3 \mathrm{~m}(30.8 \mathrm{~m}$ below the ground surface) north-eastern the study area. In contrast, the maximum depth of the bed rock is R.L. $-44.5 \mathrm{~m}$ ( $46.88 \mathrm{~m}$ below the ground surface) in the core of the study area. Geologically, therefore, there is an obvious geosyncline basin occurring in the core of the study area. The hypothesis that leads to this finding is the gradual decrease in the depth of the bed rock towards the centre of Surfers Paradise.

Moreover, the physical and engineering properties of the peat layer in Surfers Paradise has been compared and correlated with the properties of peat reported in tropical peat represents decomposed remains of plants which have certain ranges of physical and engineering magnitudes (water content, bulk density, water content, compression characteristics etc.) differ from peat in other regions. In addition, validation of the results obtained from the SPT-N zonation maps produced by ArcMap is continuing as this paper is a part from $\mathrm{PhD}$ research to characterise the peat layer is Surfers Paradise.

\section{CONCLUSION}

- This study examined 8 interpolation techniques in the Spatial Analyst extension in ArcMap10 to assess which interpolation method provides better representation for the soil data in the study area. This examination showed that the Inverse Distance Weighting (IDW) technique provides better representation to the data of the Standard Penetration Test SPT- $N$ value in the study area among 8 interpolation techniques with certain parameters. These parameters were: output cell size is " $2.719 \mathrm{E}^{-05}$ ", power is " 2 ", search radius is "fixed" and distance is " 0.25 ".

- The depth and the extent of the peat layer have been determined by performing two different directions cross sections in the core of the study area where most of the high rise buildings are erected. These cross sections showed that peat layer occurs in varying thickness as an embedded layer within the very dense sand layers at depths between R.L. $-10 \mathrm{~m}$ to $-19.6 \mathrm{~m}$ in the study area. This peat layer is highly compressible with low shear strength and has high moisture content which is considered as a geotechnically problematic layer.

- The physical and engineering properties of peat and soil in Surfers Paradise fall within the range of the properties of peat of tropical regions. 


\section{REFERENCES}

Al-Ani H., Oh E., Chai G., Al-Uzairy B.N., 2014. GIS- Interpolated Geotechnical Zonation Maps in Surfers Paradise, Australia. In $6^{\text {th }}$ International Conference on Advanced Geographic Information Systems, Applications, and Services (GEOProcessing 2014), Spain, Barcelona: 142-148.

Al-Ani H., Oh E., Eslami-Andargoli L., Chai G., 2013a. Subsurface Visualization of Peat and Soil by using GIS in Surfers Paradise, Southeast Queensland, Australia. Electronic Journal of Geotechnical Engineering, 18 (I): 1761-1774.

Al-Ani H., Oh E., Leila Eslami-Andargoli, Chai G., 2013b. Categorising Geotechnical Properties of Surfers Paradise Soil Using Geographic Information System (GIS). International Journal of Geomate, 5 (2): 690-695.

Al-Ani H., Oh E., Chai G., 2013c. Engineering properties of peat in estuarine environment. In Proceedings of $1^{\text {st }}$ International Conference on Foundation and Soft Ground Engineering Challenges in Mekong Delta, Vietnam: 181-191.

Al-Ani H., Oh E., Chai G., 2013d. Characteristics of Embedded Peat in Coastal Environments. International Journal of Geomate, 5 (1): 609-618.

Deaton S.L., Frost J.D., Luna R., Parsons R.L., 2001. Geographic Information System-Based Evaluation of Geotechnical Borehole Log Quality. Transportation Research Board TRB, 1755: 15-25.

Duraisamy Y., Huat B.B.K., Aziz A.A., 2007. Engineering Properties of Compressibility Behaviour of Tropical Peat Soil. American Journal of Applied Sciences, 4 (10): 768-773.

GCCC, Gold Coast Coty Council, 2011. Planning Report - Tugun to Bilinga Oceanway. QLD, Australia.

Gotway C.A., Ferguson R.B., Hergert G.W., Peterson T.A., 1996. Comparison of Kriging and Inverse-Distance Methods for Mapping Soil Parameters. Soil Science Society of American Journal, 60: 1237-1247.

Ho C.L., Skeels J.O., 2003. GIS modeling of the subsurface stratigraphy. in $12^{\text {th }}$ Pan-American Conference on Soil Mechanics and Geotechnical Engineering, Cambridge, Massachusetts, USA, 22-26 June 2003.
Huat B.B.K., Asadi A., Kazemian S., 2009. Experimental Investigation on Geomechanical Properties of Tropical Organic Soils and Peat. American Journal of Engineering and Applied Sciences, 2 (1): 184-188.

Huat B.B.K., 2004. Organic and Peat Soils Engineering. Universiti Putra Malaysia Press, Malaysia: 146 pp.

Kunapo J., Dasari G.R., Phoon K.K., Tan T.S., 2005. Development of a Web-GIS Based Geotechnical Information System. Journal of Computing in Civil Engineering, 19 (3): 323-327.

L'Abate G., Allegri G., Barbera R., Bruno R., Fargetta M., and Costantini E. A. C., 2013. The ISI web-GIS application for online Italian soil data consultation. Proceedings of EFITAWCCA-CIGR Conference "Sustainable Agriculture through ICT Innovation", Turin, Italy.

Landva A.O., 2007. Characterization of Escuminac peat and construction on peatland. [In:] Characterisation and engineering properties of natural soil (Tan T.S., Phoon K.K., Hight D.W., Leroueil S., Editors), Balkema, The Netherlands, 3: 2135-2191.

Look B.G., 2007. Handbook of Geotechnical Investigation and Design Tables. Taylor \& Francis/Balkema, London: 331 pp.

Lu G.Y., Wong D.W., 2008. An Adaptive Inverse-Distance Weighting spatial interpolation technique. Computers \& Geosciences, 34: 1044-1055.

Oh E.Y.N, Huang M., Surarak C., Adamec R., Balasurbamaniam A.S., 2008. Finite element modelling for piled raft foundation in sand. The $11^{\text {th }}$ East Asia-Pacific Conference on Structural Engineering and Construction (EASEC-11), Taipei, Taiwan: $1-8$.

Orhan A., Tosun H., 2010. Visualization of geotechnical data by means of Geographic Information System: a case study in Eskisehir city (NW Turkey). Environmental Earth Science, 61: 455-465.

Santagata M., Bobet A., Johnston C., Hwang J., 2008. One dimensional compression behaviour of a soil with high organic matter content. Journal of Geotechnical and Geoenvironmental Engineering, 134(1): 1-13.

Udomsri S., 2006. Application of Computer Assisted Geopedology to Predictive Soil Mapping and its use in Assesing Soil Erosion Prone Areas. Master thesis, Thailand.

Wilson P.R. and Taylor P.M., 2012, Land Zones of Queensland. Published governmental document, QLD, Australia.

Received: October 11, 2013

Accepted: April 10, 2014 